Revista Destaques Acadêmicos, Lajeado, v. 10, n. 1, 2018. ISSN 2176-3070

DOI: http://dx.doi.org/10.22410/issn.2176-3070.v10i1a2018.1750

http://www.univates.br/revistas

\title{
DESAFIOS DAS MULHERES EM CARGOS DE LIDERANÇA
}

\author{
Fernanda Borges da Silva ${ }^{1}$, Lizete Berrá ${ }^{2}$
}

\begin{abstract}
Resumo: Os desafios profissionais das mulheres fazem parte do seu cotidiano. O estudo contempla a gestão e liderança feminina, estabelecendo relação com os cargos das mulheres nas empresas. Os objetivos consistem em verificar o perfil das respondentes, identificar a amplitude administrativa das gestoras, verificar se a empresa possui um plano de cargos e salários, averiguar quais as maiores dificuldades enfrentadas no desempenho de suas funções e identificar de que modo às gestoras têm buscado sanar essas dificuldades. Por meio de uma pesquisa qualitativa e exploratória, foram entrevistadas dez mulheres que atuam em cargos de liderança. Quanto ao perfil das respondentes, todas estão estudando ou já tem formação, e continuam buscando conhecimento de suas áreas. O grupo 1 possui tempo médio de mandato de 10 anos e o grupo 2 de 3 anos e 2 meses. A quantidade de liderados varia de 2 a 165 pessoas, tendo predominância de mulheres. Quanto a plano de cargos e salários, quatro empresas possuem e seis não. Os desafios são: dificuldade de encontrar profissionais qualificados no mercado, as novidades que surgem no dia a dia, atualizações, receio da nova área, mudança de cargo, gestão e motivação das pessoas. Constatou-se que as gestoras têm buscado sanar essas dificuldades com boa vontade, dedicação, equilíbrio, entre outros aspectos que auxiliam na liderança nas empresas.
\end{abstract}

Palavras-chave: Desafios profissionais das mulheres. Liderança feminina. Mulheres nas organizações.

\section{INTRODUÇÃO}

No século XIX, o papel da mulher na sociedade era o de servir, cuidar da casa e da família, e o único provedor das necessidades do lar era o homem. Assim a mulher só tinha que ser mãe, esposa e dona do lar; a ela não pertencia o direito de exercer uma atividade fora de casa, principalmente se fosse remunerada.

1 Graduada em Administração pela Universidade do Vale do Taquari - UNIVATES (2017).

2 Graduada em Administração pela Faculdade de Ciências Econômicas do Alto Taquari (1994), Mestre em Engenharia de Produção pela Universidade Federal de Santa Maria (2003). 
Em 1934, a mulher começa a participar das decisões sociais, e a restrição quanto ao direito eleitoral chega ao fim. A mulher passa a participar da política, podendo votar e tendo direitos iguais perante a sociedade. Essa conquista se deu pelo fato de os homens irem para as guerras e não voltarem ou então retornarem debilitados para continuar a exercer suas atividades rotineiras, portanto, a Primeira e a Segunda Guerra Mundial contribuíram para alavancar os direitos femininos.

No ano de 1983, surgem os primeiros conselhos estaduais da condição feminina nos Estados do São Paulo e Minas Gerais, para traçar políticas públicas para as mulheres. Em 1997, as mulheres já ocupavam $9 \%$ das cadeiras da Câmara dos Deputados, semelhante ao senado e as câmaras municipais. Conforme o Instituto Brasileiro de Geografia e Estatística (IBGE), no ano de 2000 havia 169.799.170 milhões de habitantes no Brasil, e as mulheres representavam 51,31\% da população. Em 2014, foi divulgado pelo Tribunal Superior Eleitoral (TSE) que as eleitoras do sexo feminino representavam $52,13 \%$ do total de 142.822.046 eleitores.

Outra conquista das mulheres foi referente ao dia 8 de Março, data em que anualmente comemora-se o Dia Internacional da Mulher, o qual é lembrado por uma série de batalhas vividas por elas e que resultou na morte de muitas. Com isso, as leis tiveram mudanças, não só na parte trabalhista, mas também em relação à participação mais assídua da mulher na sociedade.

Conforme dados do Cadastro Geral de Empregados e Desempregados (CAGED) e da Relação Anual de Informações Sociais (RAIS) em 2016 havia 44\% de mulheres empregadas, e de acordo com o IBGE, entre 2012 e 2016, o total de homens empregados sofreu redução de $6,4 \%$, contra 3,5\% entre as mulheres.

Os dados do IBGE de 2017 apontam, quanto ao gênero e cargos de liderança, que as mulheres ocupam 31,3\% de cargos gerenciais e os homens $68,7 \%$. Já em cargos que envolvem a presidência ou direção, a diferença é maior, os homens equivalem a $86,4 \%$ e as mulheres a $13,6 \%$.

Nos últimos anos no Brasil e em outros países, os dados vêm mostrando que a atuação de mulheres nas empresas só tem aumentado, principalmente em cargos de liderança. O Peterson Institute for International Economics, uma instituição sem fins lucrativos, em parceria com a Ernst $\mathcal{E}$ Young (EY), uma das maiores empresas de serviços profissionais do mundo, pesquisou 21.980 empresas em 91 países e concluiu que a presença das mulheres na liderança de uma corporação pode melhorar o desempenho. A pesquisa mostra que um aumento de 0 a 30\% de mulheres em cargos de liderança associa-se a um aumento de $15 \%$ da lucratividade.

No cenário atual, mulheres e homens que ocupam cargos de liderança na mesma posição muitas vezes são vistos com diferença tanto em gênero como em valorização salarial e técnica. Algumas empresas desenvolvem plano de cargo, salário e carreira, a fim de não fazerem discriminação. 
O tema foca-se na gestão e liderança, sendo a gestão entendida como o ato de administrar, e a liderança como o ato de conduzir um grupo de pessoas, influenciando-o de maneira a estar motivado a executar o que foi proposto, a fim de cumprir um objetivo maior.

Diante do exposto, o presente estudo tem como objetivo geral: Identificar os maiores desafios profissionais das mulheres em cargos de liderança. E quanto aos objetivos específicos, verificar o perfil das respondentes, identificar a amplitude administrativa das gestoras, verificar se a empresa possui um plano de cargos e salários, averiguar quais as maiores dificuldades enfrentadas no desempenho de suas funções e identificar de que modo às gestoras têm buscado sanar essas dificuldades.

A pesquisa foi realizada em empresas de médio porte ${ }^{3}$, nas quais atuem mulheres e homens em cargos de liderança, na cidade de Lajeado/RS, no período de agosto a outubro de 2017.

\section{A MULHER NO MERCADO DE TRABALHO: BREVE HISTÓRICO}

As autoras Schlickmann e Pizarro (2013), destacam que as tradições anteriores davam ao homem o direito de ser o único provedor das necessidades da casa; para as mulheres ficava somente a obrigação da organização do lar. Assim, a elas não cabia o direito de trabalhar fora, principalmente se fosse para ganhar dinheiro, tampouco contavam com o direito de participar das decisões sociais.

"A filosofia considerava que a inferioridade da razão entre as mulheres era fato incontestável, cabendo a elas apenas cultivá-la na medida necessária ao cumprimento de seus deveres naturais: obedecer ao marido e cuidar dos filhos" (SINA, 2005, p. 21).

Conforme Tonani (2011), no passado, uma mulher inserida no mercado de trabalho era difícil de ser visto, uma exceção, qualquer ficha cadastral feminina, localizava-se no campo "profissão" a descrição "do lar" ou "doméstica."

"As primeiras normas brasileiras de proteção ao trabalho da mulher constam da Consolidação das Leis do Trabalho (CLT), de 1943, e impunham restrições às atividades extraordinárias, noturnas, insalubres e perigosas" (COHEN, 2009, p. 167).

Tonani (2011) destaca que antigamente, a mulher era vista como rainha do lar, e as organizações sociais tinham como composição familiar o homem

3 Utiliza-se como referência de médio porte a definição do Serviço Brasileiro de Apoio às Micro e Pequenas Empresas (SEBRAE), que delimita 50 a 99 funcionários se for no ramo de comércio ou serviços e 100 a 499 se for indústria, e o faturamento anual na faixa de $R \$ 16.000 .000,00$ e $\mathrm{R} \$ 90.000 .000,00$. 
como o único provedor. A mulher não tinha um trabalho para o qual ela saísse de casa como o homem, apenas exercia atividades rotineiras.

Coutinho, afirma que:

[...] foi somente no início do Século XX, contudo, que as mulheres brasileiras das camadas médias começaram a atuar nas empresas, preenchendo funções de apoio (secretárias, por exemplo) enquanto aguardavam e/ou se preparavam para o casamento, ainda que algumas permanecessem no trabalho mesmo depois de casadas, especialmente antes do nascimento dos filhos, para aumentar a renda familiar. Pouco a pouco, a despeito da permanência da segregação a que sempre foram submetidas na esfera pública, elas foram abrindo espaço e ganhando posições mais elevadas nas empresas. Após anos de exclusão aberta das posições de poder e autoridade, já encontramos, no país, mulheres ocupando posições de destaque, ainda que a exclusão persista, mesmo que, na maioria das vezes, de forma velada (COUTINHO, 2011, p. 62).

"A luta da mulher por melhores condições de trabalho e por sociedades mais justas e igualitárias é antiga e contou com a participação de grandes personagens femininas ao longo da história" (COHEN, 2009, p. 161).

Cohen descreve: "Às mulheres tampouco era facultado aprender a ler. Quando aprendiam algo, era nas escolas administradas pela Igreja que desenvolviam habilidades manuais e domésticas" (COHEN, 2009, p. 165).

\section{A EVOLUÇÃO DOS DIREITOS FEMININOS: LUTAS X CONQUISTAS}

Na visão de Tonani (2011), muito se ganhou com o surgimento dos novos formatos familiares, onde a figura masculina antes era vista como o único provedor e a feminina como responsável somente pela condução do lar e da criação dos filhos. Com as mudanças, os lares passaram a ser chefiados por mulheres, casais começaram a dividir compromissos e responsabilidades e, como resultado, a mulher se tornou cada vez mais participativa econômica e socialmente.

"Uma das grandes bandeiras das pensadoras e ativistas que defendiam os direitos femininos era a questão do voto." (SINA, 2005, p. 27). "O objetivo do voto era então incentivar e zelar pela participação feminina na vida social, econômica e política das nações" (COHEN, 2009, p. 165). "No Brasil, as mulheres passaram a ter direito a voto em 1933, nos primórdios da chamara Era Vargas" (SINA, 2005, p. 28).

A autora Cohen (2009), comenta que o século XX, testemunharia alguns marcos importantes na luta pela emancipação feminina, a exemplo do artigo $2^{\circ}$ da Declaração Universal dos Direitos Humanos, de 1948, que proclamou 
que todos os seres humanos têm direitos e liberdades iguais perante a lei, sem distinção de nenhum tipo, raça, cor e sexo.

Temóteo (2013) destaca que há diferenças salariais entre homens e mulheres, e o pior de tudo é que quanto maior a renda, maior é a diferença. O problema relaciona-se ao exercício de poder e liderança dentro de uma empresa.

Para Castells (1999), a inserção da mulher no mercado de trabalho modificou tanto o mercado como também a família. Ele se refere ao crescimento da economia, onde se evidenciam as oportunidades de educação; às mudanças tecnológicas, estando à gravidez, a reprodução da espécie; o desenvolvimento do movimento feminista com busca por direitos e, por último, a difusão das ideias de globalizada.

O autor Castells (1999), ainda complementa que a diferença entre o modo de trabalho do homem e da mulher excede questões biológicas, o que se relaciona com os fatos sociais de que a mulher tem vantagem no mercado diante da crise do emprego, pois há a possibilidade de pagar menos pelo mesmo trabalho prestado pelo homem e que ela possui flexibilidade no horário.

Segundo Schlickmann e Pizarro (2013), as mulheres conseguiram vencer as barreiras do papel incumbido a elas, o de serem apenas esposas, mães e donas do lar. Isso tudo foi possível perceber com maior intensidade, a partir da década de 70, quando o público feminino foi conquistando profissões mais bem conceituadas e com maior responsabilidade e um ganho, foi à mulher na politica.

\section{LIDERANÇA E GESTÃO FEMININA}

Conforme Chiavenato (2004), o termo liderança significa o processo de coordenar o desempenho das pessoas, dando rumo ao alcance de alguns objetivos estabelecidos. É a capacidade de dirigir e conduzir outras pessoas a buscar resultado a partir de seu comportamento.

Maxwell afirma: "Saber ouvir gera bons resultados. Quanto mais você sabe, melhor você se torna. Quando os líderes ouvem, eles têm acesso ao conhecimento, às percepções, à sabedoria e ao respeito dos outros" (MAXWELL, 2008, p. 68).

Josette apud Cohen (2009) comenta que as diferenças entre homens e mulheres aparecem claramente quando se foca a carreira, pois os homens constroem um futuro profissional e as mulheres lidam com dupla jornada, profissional e familiar. Assim, as mulheres evoluíram no universo profissional, não sendo mais consideradas talentos de segunda categoria ou homens vestidos de saia; elas são vistas como culturas diferentes (entre masculina e feminina), o que não se discute em gênero, mas são analisadas outras características e aspectos. 
Uma relação de habilidades que os líderes potenciais demonstram:

Entre elas aparecem: Capacidade de adaptação: ajustam-se rapidamente às mudanças; discernimento: compreendem quais são as questões mais importantes; perspectiva: enxergam além do ponto em que estão; comunicação: interagem com as pessoas de todos os níveis da organização; segurança: confiam no que são, e não no cargo que ocupam; disposição para servir: fazem o que for necessário; iniciativa: encontram maneiras criativas de fazer as coisas acontecerem; maturidade: colocam a equipe em primeiro lugar; persistência: mantêm consistência em termos de caráter e competência a longo prazo e confiabilidade: são dignos de confiança naquilo que é mais importante (MAXWELL, 2008, p. 109).

Conforme Kets de Vries (1997), os talentos das mulheres são nítidos, e as empresas que aparecem no mercado, em sua maior parte indicam que as mulheres possuem habilidades que são sob medida para o perfil procurado num líder gestor.

Fischer (2001) descreve que as mulheres possuem um talento natural, onde há a apetência, o desejo pelo trabalho em rede e pela arte da negociação. Também a compreensão, a sensibilidade emocional e a empatia, a eficiência de conciliar várias funções e tarefas e a aptidão de comunicação verbal, o dom de comunicar-se, relacionam-se ao perfil necessário de um líder do século XXI.

Recchia (2007), consultor da Calyper Estratégias Humanas do Brasil juntamente com a HSM Educação Executiva, realizou uma pesquisa do perfil da executiva brasileira, fazendo levantamento com 66 mulheres que ocupavam cargos de presidência, vice-presidência e diretoria, e destacou os dados, conforme segue.

Quadro 1 - Diferenças entre estilos de gestão feminino e masculino

\begin{tabular}{|l|l|}
\hline Diferenças entre estilos de gestão feminino e masculino & (\%) Perfil \\
\hline $\begin{array}{l}\text { A mulher busca o bem-estar das pessoas (maternal) e o homem é mais } \\
\text { orientado para si próprio. }\end{array}$ & $25 \%$ \\
\hline $\begin{array}{l}\text { A mulher consegue administrar inúmeras atividades, olhar tudo de forma } \\
\text { mais ampla, enquanto o homem é mais focado e objetivo. Mas a mulher } \\
\text { sabe quando é necessário focar. }\end{array}$ & $15 \%$ \\
\hline A mulher é mais intuitiva. & $13 \%$ \\
\hline $\begin{array}{l}\text { A mulher é mais humana, dócil, usa mais a emoção. Os homens são mais } \\
\text { frios, práticos, calculistas. O homem é mais focado no poder. }\end{array}$ & $12 \%$ \\
\hline A mulher é mais detalhista. & $8 \%$ \\
\hline A mulher é mais ágil e tem maior facilidade na tomada de decisão. & $5 \%$ \\
\hline A mulher tem mais flexibilidade. & $5 \%$ \\
\hline
\end{tabular}




\begin{tabular}{|l|l|}
\hline Diferenças entre estilos de gestão feminino e masculino & (\%) Perfil \\
\hline Sob o ponto dos negócios são equivalentes, não há diferenças. & $5 \%$ \\
\hline A mulher tem mais capacidade de ver e ouvir mais do que a do homem. & $3 \%$ \\
\hline A mulher tem mais paciência para esperar resultados em longo prazo. & $3 \%$ \\
\hline A mulher consegue buscar de cada profissional o que tem de melhor. & $2 \%$ \\
\hline A mulher dá mais voltas para chegar onde quer. É menos direta. & $2 \%$ \\
\hline $\begin{array}{l}\text { A mulher frente a um problema respira, pensa e consegue buscar soluções. } \\
\text { O homem é mais ansioso. }\end{array}$ & $2 \%$ \\
\hline
\end{tabular}

Fonte: Caliper (2007, p. 15).

“O perfil da mulher que exerce um cargo de liderança é bem diferente de alguns anos atrás. Elas estão ambiciosas e possuem uma rede de relacionamento de causar inveja" (COHEN, 2009, p. 30).

Segundo Cohen (2009), as mulheres possuem um quociente de inteligência (QI) e um quociente emocional (QE) elevados, que se sobressaem aos dos homens. A mulher possui no QI: fluência verbal e na expressão de ideias, bom intelecto e senso estético, tendência à introspecção, ansiedade e culpa e comedimento; e no QE: positivas em relação a si mesmas, comunicativas e gregárias, boa adaptação à tensão, espontaneidade. O autor relata que esse perfil pode ter grau variado nas mulheres, mas que todas possuem um pouco de cada característica citada.

\section{COMPETÊNCIAS E HABILIDADES}

Em Chiavenato (2004), há um detalhamento de competências relativas à desempenho de liderança, ao ato de liderar (elas são o estímulo ou motivação para seguir os objetivos), a encorajamento para liderar, à integridade (onde se inclui confiabilidade e ânimo para gerar a transformação de simples palavras em ações), à autoconfiança para conduzir os liderados e fazer com que eles se sintam mais confiantes e motivados, à inteligência (onde o foco é na habilidade do processo de informação, analise de alternativas e descoberta de oportunidades).

Conforme Tonani, "o mercado procura obter de seus líderes competências que os aproximem de suas equipes e as motivem para trabalharem como um verdadeiro time, de forma complementar e equilibrada" (TONANI, 2011, p. 6).

Para Antunes (2001), as competências não são inatas, e por isso são atributos que podem ser constituídos e adquiridos durante a vida. “Competência, segundo o dicionário, vem do latim competentia, e significa a qualidade de quem é capaz de apreciar e resolver certo assunto, fazer determinada coisa, capacidade, habilidade, aptidão e idoneidade" (FERREIRA, 1995, p. 353). 
As competências do CHA (QUADRO 2) podem garantir um diferencial competitivo, tanto para homens como para mulheres:

Quadro 2 - Competências CHA

\begin{tabular}{|l|l|l|}
\hline & Competências & Definição \\
\hline C - Saber & Conhecimento & $\begin{array}{l}\text { Conhecimentos técnicos, escolaridade, } \\
\text { cursos e especializações, etc. }\end{array}$ \\
\hline H - Saber fazer & Habilidades & $\begin{array}{l}\text { Experiência nos conhecimentos técnicos, } \\
\text { ter colocado em prática o saber. }\end{array}$ \\
\hline A - Querer fazer & Atitude & $\begin{array}{l}\text { Ter atitudes compatíveis para atingir } \\
\text { eficácia em relação aos conhecimentos e } \\
\text { habilidades adquiridos ou a ser. }\end{array}$ \\
\hline
\end{tabular}

Fonte: Rabaglio (2001, p. 6).

Segundo Borba et al. (2011, p. 4), as competências seriam então um conjunto destes três elementos: 1 . Conhecimento $=$ Saber. $\mathrm{O}$ conhecer não definitivo, ou seja, a busca constante em aprender e sempre aumentar o conhecimento. 2. Habilidade $=$ Saber fazer. Usar o conhecimento para resolver problemas e ter criatividade para criar novas ideias. 3 . Atitude $=$ Competência = Saber fazer acontecer. É obter bons ou excelentes resultados do que foi feito com conhecimento e habilidade.

Segundo Fleury (2013), os elementos considerados para caracterizar o gerenciamento feminino são: organização (o ambiente, o trabalho), competência (a mulher chegou onde está pela sua capacidade), compreensão (olha a pessoa como um todo, e não apenas profissional), indiferença e flexibilidade.

Assim, os homens são melhores em inovação e manipulação de materiais, e as mulheres se destacam em promover a união e a não é superior ao outro cooperação, afinal, um. A proposição de um modelo feminino ou masculino é algo em construção. "Mesmo a passos largos, ainda falta consenso de que, homens e mulheres têm suas próprias competências, que os tornam habilidosos em sua forma particular de liderar" (TONANI, 2011, p. 11).

Para Chiavenato (2004), existem três habilidades que necessariamente os gestores devem possuir: técnicas, humanas e conceituais. Elas ajudam na visão total da organização, auxiliam na administração, no processo de tomada de decisão, nos objetivos e também ao utilizar os recursos.

Katz (1974) classificou as habilidades dos gestores em três (FIGURA 1), destacando serem essenciais aos administradores, devido a sua importância e variando conforme o nível de responsabilidade gerencial. 
Figura 1 - Habilidades técnicas, humanas e conceituais:

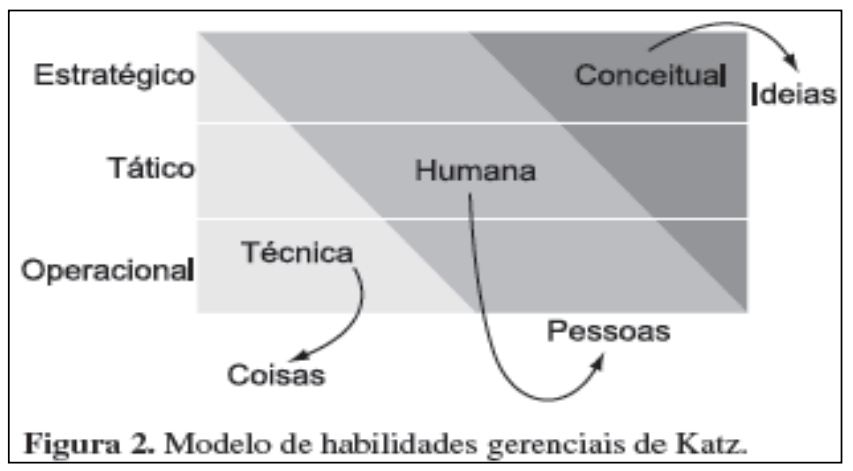

Fonte: Katz (1974, p. 152).

Para Oderich (2005), habilidades técnicas são os exercícios de atividades que dão representação ao conhecimento específico, associado a um cargo gerencial.

Segundo Katz (1974), as habilidades humanas estão relacionadas com o saber lidar com pessoas e manter um relacionamento grupal com elas, envolve a comunicação, a coordenação, a liderança e a facilidade para resolução de conflitos; é a sabedoria de trabalhar com pessoas e por meio delas.

Para Katz (1974), a habilidade conceitual estrutura a compreensão das complexidades da organização total e não só os objetivos e necessidades de seu grupo, é ter a visão do todo e trabalha com os assuntos de longo prazo.

\section{A MULHER NO PAPEL DE LÍDER NAS ORGANIZAÇÕES}

Sina (2005), salienta que quando a mulher opta pela carreira executiva, nas corporações, é capaz de ir aos detalhes sem dificuldade, e tantas vezes quantas forem necessárias, o que é muito mais complicado aos homens.

De acordo com Fleury (2013), o modelo de liderança feminino é voltado para promover a união e cooperação e o modelo masculino somente vê a inovação, porém, um não é superior ao outro e podem conter traços que se complementam.

Para Fonseca (2002), as mulheres valorizam o trabalho em equipe, são mais perseverantes, são pouco imediatistas e muito capazes de pensar a longo prazo, possuem facilidade de viver em apertos, em tempos difíceis, possuem abertura para ideias e grande flexibilidade para aprendizado, o que as faz líderes de forma natural.

Renesch (2003) destaca qualidades que compõem o estereótipo de liderança feminina: - Harmonia e delicadeza - Concordância que gera acordos e não conflitos. E se os homens são donos do "hemisfério esquerdo", às 
mulheres cabe o "hemisfério direito". Isso implica uma capacidade de ver o todo, equilibrar, exercer a criatividade, raciocinar e pensar pela intuição. Mulheres são sutis e frágeis, foram educadas para serem gentis e delicadas com as pessoas.

- Cooperação - Auxiliar e cooperar a fim de um objetivo maior. Isso vem da personalidade feminina, pois as mulheres foram criadas para "ajudar" na casa. Nas brincadeiras de infância (pular corda, brincar de casinha ou de boneca), cada uma tinha a sua vez, a menina sempre respeita as outras. A menina boazinha era a que "ajudava a mamãe" e estava disposta a sempre colaborar.

- Pôr o grupo em primeiro lugar - Presença de sensibilidade intuitiva, onde o primeiro é o todo. As meninas eram encorajadas a fazerem-se queridas, por tantos quanto possível. Dever de ver o grupo e não o individual. O objetivo era ser a mais popular, e pensar em si mesmo era tido como "egoísta". Se na escola demonstrava prazer em ganhar recebia o rótulo de "exibida", o que era visto como individualismo.

- Maternal - Sempre a mãe de todos. Fazer o papel de mãe das bonecas mostrava a importância de exercer o papel de cuidadora. Cuidar de crianças pequenas era, com frequência, a primeira experiência profissional, onde aprendiam a ter responsabilidades, quando o conceito de habilidade e competência afetiva.

\section{OS MAIORES DESAFIOS PROFISSIONAIS DAS MULHERES}

Segundo Sina (2005), um desafio do perfil feminino é que uma mulher espera de si mesma, antes de tudo, coragem e energia para ser; portanto, essa exigência a faz querer sempre mais, intimando-a crescer e evoluir, não se acomodando.

Conforme Temóteo (2013), o machismo e o preconceito são os motivos principais que dificultam o poder do sexo feminino nas empresas. Outro problema são homens que dizem ficarem constrangidos quando são liderados por mulheres.

"Se paralelamente, o mercado valoriza as características consideradas predominantes nas mulheres, seus pares tendem a questionar sua real competência" (TONANI, 2011, p. 8).

Para, Rodrigues e Silva:

As mulheres têm que provar diariamente que são tão competentes e qualificadas quanto os homens para conseguirem manter-se em suas funções, submetendo-se até mesmo, a assumir posturas tidas como "masculinas" para firmar-se em suas posições. Essa briga por direitos iguais é equivocada para a mulher hoje e, a luta deve ser pela igualdade de direitos civis e sociais, e pela valorização 
financeira e moral da capacidade feminina no desenvolvimento em toda a sociedade, tanto pessoal como profissional (2015, p. 4).

Para Amazonas (2013), uma tarefa é a administração do tempo necessário que cada responsabilidade requer. Quando a mulher conquista seu espaço no mercado ela também possui vida familiar, que dá trabalho e necessita muito do seu tempo, porém faz a separação e o equilíbrio da vida pessoal e profissional.

Tonani (2011) observa que a mulher tem a necessidade constante de provar não somente sua competência individual, mas submeter-se também, "apesar" de ser mulher. Por vezes, é alvo de comentários jocosos, não sendo dado a elas o merecido valor, colocando em questão sua competência, duvidando de sua capacidade de ser enérgica, de comandar, de se impor, modificando seus atributos singulares como elementos desqualificadores para o desempenho de sua liderança.

A autora Sina (2005) destaca que, no Brasil, as mulheres sonham em abrir seus próprios negócios; porém, os dilemas das que conseguem não são muito diferentes daqueles enfrentados pelas executivas, com especial ênfase para a divisão trabalho-família, que de resto existe em todas as circunstâncias.

No mercado de trabalho e na sociedade, um desafio enfrentado é a competição e a comparação com outras mulheres. Muitos atributos geram uma concorrência entre mulheres. Dickson destaca:

Os atributos são: atratividade, onde entra aparência, forma do corpo, tom de pele, idade, cabelos e feminilidade; inteligência, que abrange formação, trabalho, experiência e especialização; condição social, status do marido e número de filhos; personalidade, confiança, postura e por fim, situação financeira, que engloba roupas e poder aquisitivo (DICKSON, 2001, p. 143).

\section{PROCEDIMENTOS METODOLÓGICOS}

A elaboração de uma pesquisa sujeita o problema a ser averiguado, sua classe, tempo e localização em que se constata o grau de capacidade. Conforme Gil pesquisa pode ser entendida da seguinte forma:

Pode-se definir pesquisa como o procedimento racional e sistemático que tem como objetivo proporcionar respostas aos problemas que são propostos. A pesquisa é requerida quando não se dispõe de informação suficiente para responder ao problema, ou então quando a informação disponível se encontra em tal estado de desordem que não possa ser adequadamente relacionada ao problema (GIL, 2002, p. 17). 
Quanto aos objetivos, a pesquisa determina-se como exploratória. Para Gil (2008), a pesquisa exploratória proporciona maior familiaridade com o problema.

Quanto a abordagem da natureza, a pesquisa é qualitativa. Segundo Malhotra (2005), a pesquisa qualitativa permite a visão e percepção do contexto do problema, ou seja, as informações extraídas são totalmente interligadas para fim de uma análise geral.

Quanto aos procedimentos técnicos, o estudo caracteriza-se como entrevista do tipo survey. Para Fonseca (2002), a pesquisa com survey pode ser referida como sendo a obtenção de dados ou informações sobre as características ou opiniões de determinado grupo de pessoas, indicado como representante de uma população-alvo, utilizando um roteiro de entrevista como instrumento de pesquisa.

O quadro a seguir apresenta as questões e de que forma elas respondem ao referencial teórico e aos objetivos propostos.

Quadro 3 - Distribuição das questões quanto ao referencial teórico e objetivos:

\begin{tabular}{|c|c|c|c|}
\hline Objetivo Geral: & $\begin{array}{l}\text { Objetivos Específicos: } \\
\text { Levantar o perfil das } \\
\text { respondentes; }\end{array}$ & $\begin{array}{l}\text { Referencial Teórico: } \\
\text { Competências; Habilidades. }\end{array}$ & $\begin{array}{l}\text { Questões: } \\
1 \text { a } 6\end{array}$ \\
\hline $\begin{array}{l}\text { Identificar quais } \\
\text { os maiores } \\
\text { desafios } \\
\text { profissionais } \\
\text { das mulheres } \\
\text { em cargos de } \\
\text { liderança. }\end{array}$ & $\begin{array}{l}\text { Identificar a amplitude } \\
\text { administrativa das } \\
\text { gestoras; } \\
\text { Verificar se a empresa } \\
\text { possui um plano de } \\
\text { cargos e salários; }\end{array}$ & $\begin{array}{l}\text { Liderança e gestão feminina. } \\
\text { A evolução dos direitos } \\
\text { femininos: lutas x conquistas. } \\
\text { Os maiores desafios profissionais } \\
\text { das mulheres. }\end{array}$ & $\begin{array}{l}7 \text { a } 9 \\
10 \text { a } 12 \\
13 \text { a } 15\end{array}$ \\
\hline & $\begin{array}{l}\text { Averiguar quais as } \\
\text { maiores dificuldades } \\
\text { enfrentadas no } \\
\text { desempenho de suas } \\
\text { funções; } \\
\text { Identificar de que modo } \\
\text { às gestoras têm buscado } \\
\text { sanar essas dificuldades. }\end{array}$ & $\begin{array}{l}\text { A mulher no papel de líder nas } \\
\text { organizações; } \\
\text { A mulher no mercado de } \\
\text { trabalho: breve histórico }\end{array}$ & 16 a 18 \\
\hline
\end{tabular}

Fonte: Autora, quadro elaborado com base na pesquisa (2017).

\section{ANÁLISE E APRESENTAÇÃO DOS RESULTADOS}

Em relação ao perfil do grupo 1, é possível perceber que o tempo de atuação em cargos de liderança ou gestão é de mais de 6 anos e que estão no 
segundo mandato ou já atuaram mais de duas vezes nesses cargos. Glaucia é a participante desse grupo com menor tempo de atuação, no caso 6 anos, mas já tem mais de dois mandatos. Já Manuela atua há 9 anos, Adriane 10 anos, Maristela 11 anos e Katieli 14 anos. Desse modo, o tempo médio em cargos de liderança das respondentes do grupo 1 corresponde a 10 anos.

Glaucia e Manuela são formadas em Recursos Humanos, e Manuela está fazendo especialização em Gestão de Pessoas. Maristela, Katieli e Adriane são formadas em Administração de Empresas, mas Adriane está cursando pós em Gestão Comercial e Katieli tem também MBA em Gestão de Pessoas com Ênfase em Estratégias e Pós Graduação em Direito Processual.

No grupo 2, em se tratando em atuação, há uma variação de 1 a 5 anos. Neste grupo, a de maior tempo é Antônia com 5 anos e Ariane com menor tempo, que trabalha há um ano e está no seu primeiro mandato. Luciana trabalha há dois anos e está no segundo mandato. Raquel e Júlia atuam há quatro anos e ambas estão no primeiro mandato. Dessa forma, o grupo 2 tem tempo médio de 3 anos e 2 meses. Assim, como a maioria delas está no seu primeiro mandato ou iniciando no segundo, pode-se dizer que o nível de experiência é médio.

Sobre a formação de cada integrante, Ariane e Luciana estão cursando atualmente Administração de Empresas. Raquel é formada em Ciências Contábeis e está cursando pós em Gestão Tributária. Antônia é formada em Relações Públicas e está cursando MBA em Gestão Empresarial. Júlia é técnica em Tratamento de Resíduos Industriais, bacharel em Química Industrial e Mestre em Biotecnologia.

No que tange à amplitude administrativa do grupo 1, percebe-se que as equipes, em média, contam com 10 liderados, porém, Glaucia tem sua equipe de trabalho, da qual ela é chefe, e também atua como supervisora, de forma indireta, de 165 profissionais na empresa, pois há outra responsável junto com ela nessa função. Então, considerou-se somente as duas lideradas para calcular a média.

O grupo 1, tem total de 21 homens liderados e de 20 mulheres. Nas equipes, três predominam homens e em duas equipes predominam mulheres.

O grupo 2, a média de liderados, fica num total de 21, afinal Ariane possui 56 liderados e Júlia 20. Já analisando a predominância de homens e mulheres, em 4 equipes predominam mulheres e em uma homens. Assim, no total do grupo 1 e 2, quatro equipes predominam homens e seis equipes predominam mulheres.

O plano de cargos e salários está presente neste trabalho como objetivo, devido a sua importância dentro das empresas e porque tem tudo a ver com o tema proposto. A intenção é verificar se há ou não diferenciação por gêneros.

No grupo 1, duas empresas não têm plano de cargos e salários e 3 empresas já possuem. Para Glaucia mesmo não tendo na sua empresa, ela reconhece que o plano de cargos e salários "motiva os funcionários e os estimula a 
serem ainda mais produtivos, uma vez que passam a buscar maneiras de crescer dentro da empresa."

No grupo 2, uma empresa possui plano de cargos e salários e as outras quatro não possuem. Para Júlia, o plano de cargos e salários, é "importante para a pessoa saber qual pode ser o crescimento. Ou seja, o que ela precisa para atingir outros níveis".Verificou-se que das empresas das participantes do trabalho, seis não possuem plano de cargos e salários e quatro possuem.

Em relação as dificuldades enfrentadas pelas participantes, no grupo 1 Glaucia, afirma que "os desafios são encontrar profissionais competentes e responsáveis para exercer as funções". No grupo 2, para Ariane, "o maior desafio foi assumir como gerente de uma empresa, porque as experiências que eu tinha eram de auxiliar administrativo, então foi um grande desafio."

Quanto as maiores dificuldades enfrentadas no desempenho de suas funções, as dez participantes, destacam: três participantes percebem a dificuldade de encontrar profissionais qualificados no mercado de trabalho, duas participantes dizem que as novidades que surgem no dia a dia são desafiadoras e constantes, três participantes tiveram receio da sua nova área de atuação, da mudança de cargo e das atualizações do sistema, e duas participantes relatam que a gestão de pessoas e a motivação dos funcionários é o que dificulta atualmente.

Todas participantes destacam que os desafios são necessários para crescimento profissional e gerar experiência. Analisando os problemas, todas participantes apontam como buscam sanar essas dificuldades.

No grupo 1, para Manuela, os desafios são necessários, pois são aprendizagens. Ela relata "sou muito feliz pelo que faço e acredito que tudo que surge é por algum motivo e que tenho capacidade para resolver, então enfrento com muita racionalidade e ética. Se preciso, consulto meus estudos ou os proprietários, mas sempre penso no que é melhor para a empresa."

No grupo 2, a resposta de Raquel é: "procuro resolver tudo com organização e paciência, afinal, assim tudo entra nos conformes." O que Antônia fala vem ao encontro dessas já ditas; ela relata: "procuro resolver uma coisa de cada vez, no começo do dia parece que não terá tempo para fazer tudo, mas se você realmente quiser fazer tudo ao mesmo tempo, acaba fazendo muito pouco, então coloco mais energia nos 'problemas' maiores e vou resolvendo, chega no fim do dia provavelmente tudo ficou concluído ou quase."

Quanto ao modo de como as gestoras têm buscado sanar essas dificuldades, os grupos 1 e 2 acreditam que com força de vontade tudo pode ser solucionado, e os desafios são ótimos para o crescimento profissional e agregam experiência.

Antes de tudo, a conclusão, ao ler a resposta das 10 participantes, é que o primeiro passo para sanar uma dificuldade é a boa vontade de querer resolver o problema, encontrar uma solução. 
Na entrevista, foi questionado o que é liderar na visão das participantes em geral. Adriane diz que "liderar é conduzir a equipe a concluir alguma meta, a alcançar o que foi estabelecido, o líder mostra o caminho e a equipe caminha neste, a fim de ajudar a empresa a crescer. O líder é apoiador e o facilitador."

Raquel destaca que "líder, é aquele que trabalha muito bem com as pessoas e com os recursos. Ele consegue estimular a equipe a fazer e fazer bem o que é proposto." Maristela relata: "me considero uma líder democrática, levo muito em consideração as ideias dos colaboradores, gosto de delegar responsabilidades, assim envolvendo a equipe, e meu estilo de liderança é participativa, onde ouço a opinião dos meus colaboradores."

Analisando as respostas, quase todas destacaram que um líder deve passar credibilidade, conhecer sua equipe, influenciar, motivar, ser um exemplo e que deve ajudar a equipe a alcançar seus objetivos, mostrando o caminho certo a ser seguido, e acompanhando e sendo um facilitador.

Para relacionar a fundamentação teórica deste trabalho e mostrar que, na prática, essas mulheres pensam do mesmo modo que os autores, o item 4.6 faz ligação ao que os autores Cohen (2009), Fischer (2001), Kets de Vries (1997) e Recchia (2007) mencionam no aspecto de liderança e gestão feminina, interligando ao que é liderança na visão das participantes.

Na entrevista, questionou-se, qual a importância das mulheres para as empresas e o que era o diferencial. Para Glaucia, "o diferencial das mulheres é a forma, a capacidade de gerir as pessoas, ao meu ver, considero as mulheres mais organizadas, comprometidas e batalhadoras, com olhar voltado a inovação."

Luciana relata que "a mulher tem a capacidade de se colocar no lugar do outro, a empatia. O dinamismo também é o diferencial da mulher na gestão." Na visão de Antônia "o diferencial é o tato, mulheres são mais atenciosas e acredito serem mais pacientes também." Para Júlia "a mulher possui uma maior capacidade de fazer várias coisas ao mesmo tempo."

A presença das mulheres nas empresas, possibilita a visão do todo, buscando formas mais eficientes de realizar as funções, pois a mulher é muito detalhista e observadora. Muitas relataram que a mulher é o próprio diferencial para uma empresa, e hoje é quase impossível não ter uma mulher em um cargo de liderança, as mulheres são vistas como guerreiras o que mostra que a desigualdade de gênero não deveria existir, afinal muita coisa mudou e há vários avanços conquistados.

Hoje, torna-se importante saber conciliar família e trabalho, e em uma das questões da entrevista foi questionado se elas sabiam conciliar e como faziam isso. Raquel afirma: "minha família é um bem muito precioso para mim, então gosto de gastar muitas horas com eles e não falar de trabalho. Eles compreendem meu trabalho e assim a gente vai, porque precisamos de renda, mas também de carinho, afeto e nosso lar para que todos estejam bem."

Manuela relata que "essa é a tarefa mais fácil, pois não deixo misturar, e assim aproveito o tempo para trabalhar e o tempo em casa para me divertir com minha 
família, todos deveriam pensar assim, teríamos menos problemas no mundo, de doença e de estresse. O problema todo é que os valores estão se perdendo e as famílias priorizam o trabalho e o dinheiro."

Este levantamento foi fundamental, ao ver que a mulher exerce dupla jornada, e precisa ter tempo para família e o trabalho, sem misturar. Todas as participantes mostram facilidade, priorizando no trabalho o que é daquele ambiente e não levando para casa o que é de lá, mostrando organização e controle de suas funções.

\section{CONSIDERAÇÕES FINAIS}

As mulheres ocupam posições importantes atualmente nas empresas. Hoje muitas são líderes de setores, gestoras, empresárias individuais ou sócias e assim assumem as mesmas responsabilidades que os homens, tomando para si funções que geram desafios de conduzir uma equipe, ajudar no alcance de objetivos e ainda motivá-los a querer seguir o mesmo caminho.

Em um ambiente contemporâneo e com tantas inovações, as mulheres ainda enfrentam diferenciações quanto ao gênero, ocupando os mesmos cargos e posições que os homens e recebendo salários menores. Muitas vezes, são vistas como o "sexo frágil". Por outro lado, como visto nas entrevistas, as mulheres não se vem como frágeis, e não têm medo de liderar ou tomar decisão; possuem a razão e a emoção. Nas empresas das entrevistadas, não há preconceito quanto à mulher ou homem estar ocupando uma posição de líder e na maioria dessas empresas, as mulheres são predominância nos cargos de liderança ou de gestão.

Outro aspecto que a pesquisa trouxe, foi que a mulher possui muitas características que são evidentes do perfil de um líder, o que as torna mais flexíveis e de fácil comunicação com uma equipe. Assim, como na teoria, percebe-se que as mulheres têm jeito para lidar com negociação, possuem fácil relacionamento e boa comunicação, e isso hoje é um diferencial para as empresas.

Verificou-se, desse modo, que os objetivos do estudo foram alcançados. Os desafios mudam constantemente, as participantes destacaram que sempre surge algo novo, porém estão prontas para enfrentar o que aparece. E assim, todo o estudo interligou a teoria e a prática, e permitiu vivenciar com as participantes as experiências delas e refletir sobre a fundamentação teórica.

\section{REFERÊNCIAS}

AMAZONAS, Ester. Inteligência Emocional Feminina em Alta. Semente de vida. 1. ed. Amazonas, 2013.

ANTUNES, Celso. Como desenvolver competências em sala de aula. Petrópolis: Vozes, 2001. 
ARAÚJO, Rita de Cássia Barbosa de. O voto de saias: a Constituinte de 1934 e a participação das mulheres na política. Estudos Avançados 17 (49), 2003.

BORBA, Jaqueline Sanson. MARTINS, Letícia. MUCCILLO, Ricardo Muniz. JUNIOR, Evaldo Reis Furtado. A definição dos conhecimentos, habilidades e atitudes na formação de administradores na percepção de gestores, acadêmicos e legal. VIII Congresso Virtual Brasileiro de Administração (Convibra Administração), 2011.

CASTELLS, Manuel. A era da informação: Economia, Sociedade e Cultura. O Poder da Identidade. Vol. 2. São Paulo. Editora Paz e Terra. 1999.

CHEMIN, Beatris Francisca. Manual da Univates para trabalhos acadêmicos: planejamento, elaboração e apresentação. 3. ed. Lajeado: Ed. da Univates, 2015.

CHIAVENATO, Idalberto. Gestão de Pessoas. SP. Editora Campus Elsevier, 2004.

COHEN, Marlene. Como escalar montanhas de salto alto? Exercendo no poder feminino. São Paulo: Editora Saraiva, 2009.

COUTINHO, Maria Lúcia Rocha; COUTINHO, Rodrigo Rocha. Mulheres brasileiras em posições de liderança: novas perspectivas para antigos desafios. Economia Global e Gestão v.16 n.1 Lisboa, abr. 2011.

DICKSON, Anne. Mulheres no trabalho: estratégias de sobrevivência e sucesso. São Paulo: Editora Globo, 2001.

DUARTE, Ana; D'OLIVEIRA, Teresa. GOMES, Jorge. Imperium femininis... Uma liderança de sucesso escondido. Jul/Set 2009. Revista Portuguesa e Brasileira de Gestão.

FERREIRA, A.B.H. Novo Dicionário Aurélio. Rio de Janeiro: Nova Fronteira, 1995.

FISCHER, Helen. O primeiro sexo: como as mulheres estão a mudar o mundo. São Paulo. Editora Presença, 2001.

FLEURY, Maria Teresa Leme. Liderança feminina no mercado de trabalho. CE, Agora é com elas. Vol. 12. GV Executivo, 2013.

FONSECA, João José Saraiva. Metodologia da pesquisa científica. Fortaleza: UEC, 2002 .

FRANKEL, Lois P. Mulheres lideram melhor que homens. 2. ed. São Paulo: Editora Gente, 2007.

GIL, Antônio Carlos. Como elaborar projetos de pesquisa. 4. ed. São Paulo: Editora Atlas, 2008.

IBGE. Disponível em: <http:/ / www.ibge.gov.br/home/> Acessado em: 20. mar. 2017. 
KATZ, Robert. Skills of an effective administrator. Boston: Harvard Business Review, 1974.

KETS DE VRIES, Manfred F. R. Liderança na empresa: como comportamento dos líderes afeta a cultura interna. São Paulo: Editora Atlas, 1997.

KNECHTEL, Maria do Rosário. Metodologia da Pesquisa em educação: uma abordagem teórico-prática dialogada. Curitiba: InterSaberes, 2014.

LODEN, Marilyn. Liderança feminina: como ter sucesso nos negócios sendo você mesma. São Bernardo do Campo, SP: Editora Bandeirante, 1988.

MALHOTRA, Naresh K. Introdução à pesquisa de marketing. São Paulo: Prentice Hall, 2005.

MARQUES, Vera. O chefe usa batom. Rio de Janeiro: Qualitymark Editora, 1999.

MATTAR, Fauze N. Pesquisa de Marketing. Edição Compactada. São Paulo: Editora Atlas, 1996.

MAXWELL, John C. O livro de ouro da liderança. Rio de Janeiro: Thomas Nelson Brasil, 2008.

ODERICH, Cecília. Gestão de competências gerenciais: noções e processos de desenvolvimento. Porto Alegre: Editora Bookman, 2005.

OLIVEIRA, Jair Figueiredo de. Profissão Líder: desafios e perspectivas. São Paulo: Editora Saraiva, 2006.

RABAGLIO, Maria Odete. Seleção por Competências. São Paulo: Editora Educator, 2001.

RECCHIA, José Geraldo. Perfil da Executiva Brasileira. Revista Fortuna. Santa Maria: HSM, 2007.

RENESCH, John E. Liderança para uma nova era. SP: Editora Cultrix, 2003.

RODRIGUES, Stephane Carvalho; SILVA, Gleiciane Rosa da. A liderança feminina no mercado de trabalho. Vol. 1. Revista digital de Administração Faciplac, 2015.

SCHLICKMANN, Eugênia; PIZARRO, Daniella. A evolução da mulher no trabalho: uma abordagem sob a ótica da liderança. Julho de 2013. Revista Borges. ISSN 21794308, VOL. 03, N. 01

SEBRAE. Disponível em: <https: / / www.sebrae.com.br/sites/PortalSebrae>. Acessado em: 03 abr. 2017.

SINA, Amalia. Mulher e trabalho: o desafio de conciliar diferentes papéis na sociedade. São Paulo: Editora Saraiva, 2005. 
TEMÓTEO, Antônio. Machismo e preconceito atrapalham mulheres dentro de empresas. Correio Braziliense: 2013.

TONANI, Adriana Venturim. Gestão Feminina - Um diferencial de liderança mito ou nova realidade. Agosto/2011. VII Congresso Nacional Excelência em Gestão.

TSE. Disponível em: <http:/ /www.tse.jus.br/>. Acessado em: 29. mar 2017.

VERGARA, Sylvia Constant. Projetos e relatórios de pesquisa em administração. 15. ed. São Paulo: Editora Atlas, 2014.

YIN, Robert K. Estudo de Caso: planejamento e métodos. 2. ed. Porto Alegre:

Bookman, 2001.

ZARIFIAN, Philippe. Objetivo competência: por uma nova lógica. Maria Helena Trylinski. São Paulo: Editora Atlas, 2001. 


\section{APÊNDICE A}

\section{Roteiro de entrevista semiestruturada}

1.Trabalha nesta empresa há quanto tempo? Qual o cargo que ocupa atualmente? Quantos anos atua em cargos de liderança?

2.Qual a sua idade? Qual seu estado civil? Você possui filhos? Quantos e idade. 3.Qual a jornada efetiva (não necessariamente a paga) de trabalho atualmente? 4.Qual é a formação (em que área) (níveis)?

5. Quais tuas características como líder?

6. O que é liderar para ti?

7.Quantos liderados tens atualmente? Desses quantos \% são jovens (até 35) e quantos são de meia idade (acima de 36)? Quantos \% são homens e quantos mulheres?

8.Você já teve equipes maiores?

9.Você possui um gestor acima de você? Homem ou mulher? Como é a relação de vocês? Vocês seguem o mesmo estilo de liderança?

10.Sua empresa possui plano de cargos e salários? Quais são as principais características do plano?

11. Na sua opinião, qual a importância do plano de cargos e salários para a redução das diferenças quanto ao gênero?

12.Quantos gestores (líderes, chefes de setores) há hoje na empresa? Qual a predominância, homens ou mulheres?

13.Quais as suas principais atribuições?

14.Quais seus maiores desafios/dificuldades profissionais na mesma função? Comente.

15.Quais as diferenças que você percebe quanto a homens e mulheres em cargos de liderança de um modo geral? Isso acontece, de algum modo, na tua empresa também? Se sim, como você lida com isso? Comente.

16. Quais estratégias você utiliza e qual seu estilo de liderança?

17. O que você acredita ser o diferencial da mulher na gestão de uma empresa?

Como você lida com os desafios diários?

18.O que e como você faz para conciliar o trabalho e a família? 